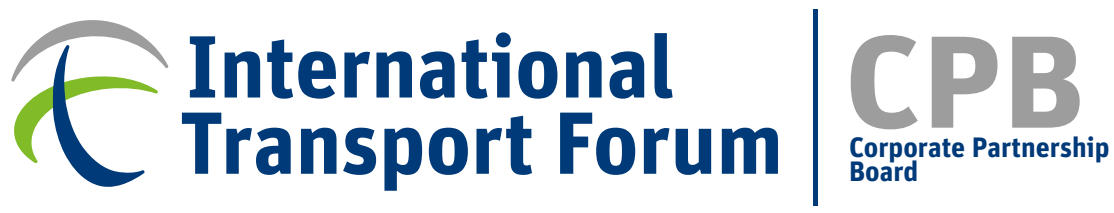

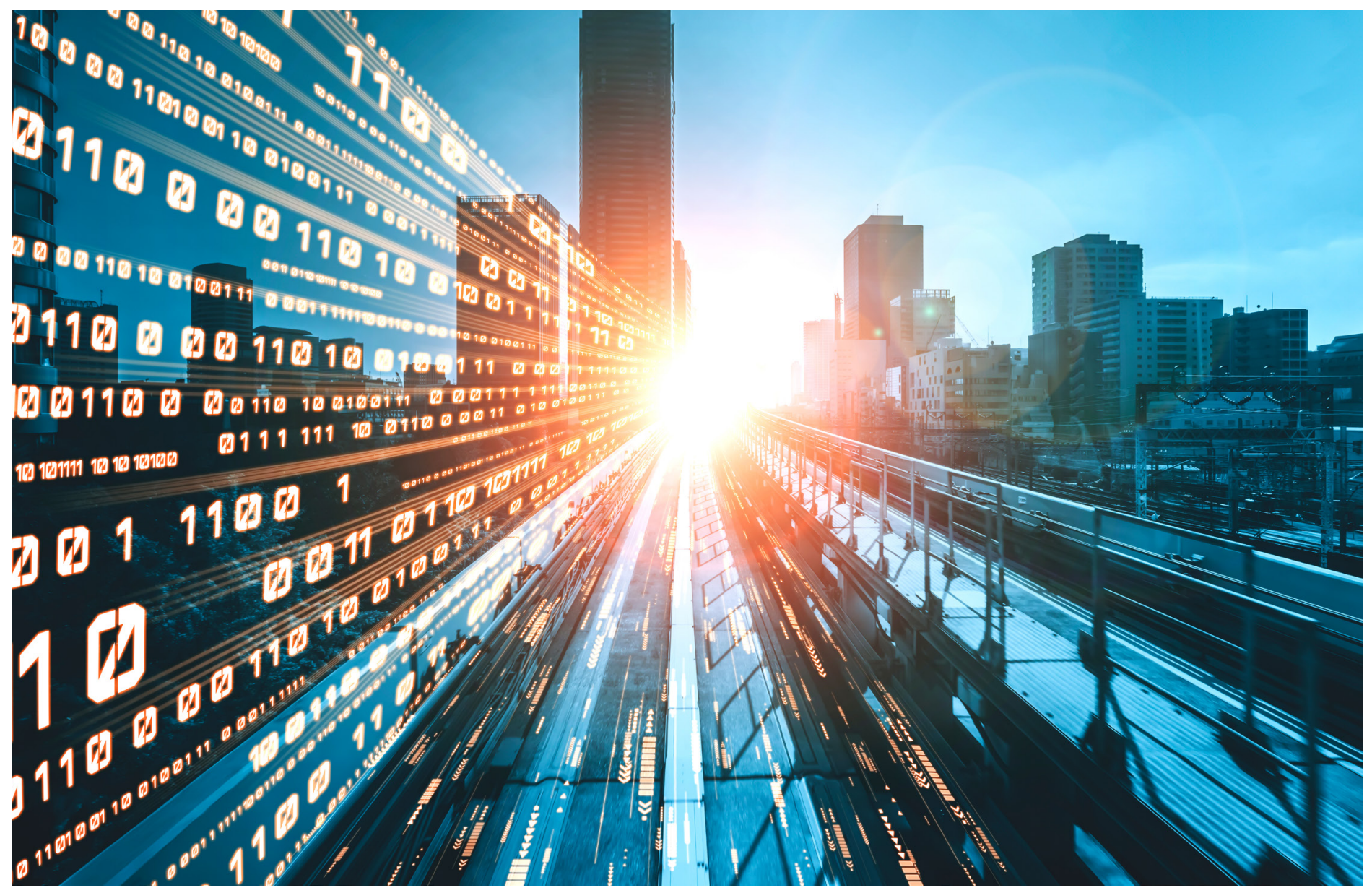

Data-driven Transport Infrastructure Maintenance

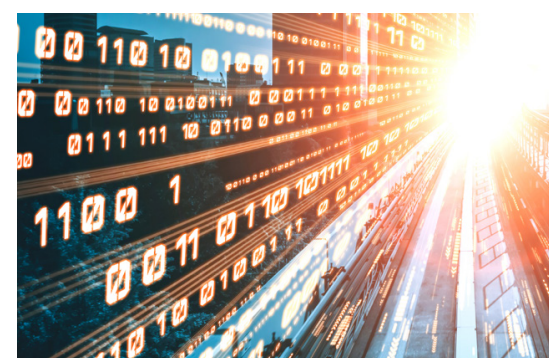

Corporate Partnership Board Report 


\section{Data-driven Transport Infrastructure Maintenance}

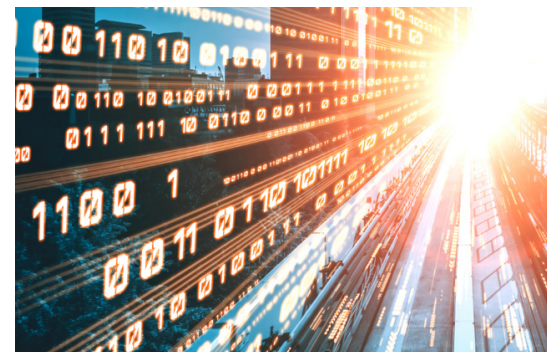

Corporate Partnership Board Report 


\section{The International Transport Forum}

The International Transport Forum is an intergovernmental organisation with 63 member countries. It acts as a think tank for transport policy and organises the Annual Summit of transport ministers. ITF is the only global body that covers all transport modes. The ITF is politically autonomous and administratively integrated with the OECD.

The ITF works for transport policies that improve peoples' lives. Our mission is to foster a deeper understanding of the role of transport in economic growth, environmental sustainability and social inclusion and to raise the public profile of transport policy.

The ITF organises global dialogue for better transport. We act as a platform for discussion and prenegotiation of policy issues across all transport modes. We analyse trends, share knowledge and promote exchange among transport decision makers and civil society. The ITF's Annual Summit is the world's largest gathering of transport ministers and the leading global platform for dialogue on transport policy.

The Members of the Forum are: Albania, Armenia, Argentina, Australia, Austria, Azerbaijan, Belarus, Belgium, Bosnia and Herzegovina, Bulgaria, Canada, Chile, China (People's Republic of), Colombia, Croatia, Czech Republic, Denmark, Estonia, Finland, France, Georgia, Germany, Greece, Hungary, Iceland, India, Ireland, Israel, Italy, Japan, Kazakhstan, Korea, Latvia, Liechtenstein, Lithuania, Luxembourg, Malta, Mexico, Republic of Moldova, Mongolia, Montenegro, Morocco, the Netherlands, New Zealand, North Macedonia, Norway, Poland, Portugal, Romania, Russian Federation, Serbia, Slovak Republic,

Slovenia, Spain, Sweden, Switzerland, Tunisia, Turkey, Ukraine, the United Arab Emirates, the United Kingdom, the United States and Uzbekistan.

\section{About the Corporate Partnership Board}

The Corporate Partnership Board (CPB) is the International Transport Forum's platform for engaging with the private sector and enriching global transport policy discussion with a business perspective. The members of the ITF Corporate Partnership Board are: AB InBev, Airbus, Allianz Partners, Alstom, Aramco, Argo Al, Arrival, AutoCrypt, Bosch, Cruise, ExxonMobil, Iberdrola, Incheon International Airport, Kakao Mobility, Michelin, NXP, PTV Group, RATP Group, Shell, Siemens, SNCF, Spea Engineering, Tier Mobility, Total Energies, Toyota, Uber, Valeo, Voi, Volvo Cars and Volvo Group.

\section{Disclaimer}

Funding for this work has been provided by the ITF Corporate Partnership Board. This report is published under the responsibility of the Secretary-General of the ITF. It has not been subject to the scrutiny of ITF or OECD member countries, and does not necessarily reflect their official views or those of the members of the Corporate Partnership Board.

Cite this work as: ITF (2021), "Data-driven Transport Infrastructure Maintenance", International Transport Forum Policy Papers, No. 95, OECD Publishing, Paris. 


\section{Acknowledgements}

This report was written by Olaf Merk of the International Transport Forum (ITF). It builds on contributions by professors Ramin Karim and Uday Kumar (Lulea University of Technology), and Maria Santos Alfageme (ITF). It was informed by two ITF workshops with members of the ITF Corporate Partnership Board, including Imogen Pierce (Arrival), Lorenzo Rossi (Autostrade), Aquilino Ponziani (Autostrade), Christophe Pouts (ExxonMobil), Carlos Bergera (Iberdrola), Jasja Tijink (Kapsch TrafficComm), Philippe Ventejol (RATP), Paulo Humanes (PTV), and Christian Irmisch (Siemens), as well as Uday Kumar (Professor Lulea University of Technology) and Faeze Ghofrani (Assistant Professor Penn State Altoona).

The author would like to thank Steve Perkins, Sharon Masterson and Philippe Crist (all ITF) and Faeze Ghofrani for their review of a draft version of the report and Hilary Gaboriau for editorial support. 


\section{Table of contents}

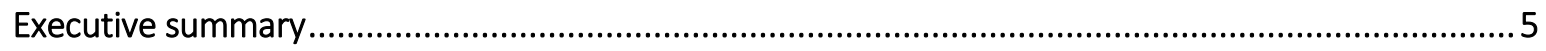

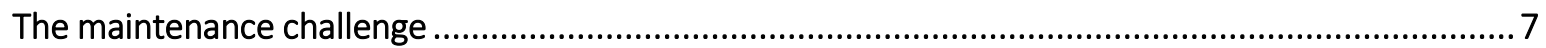

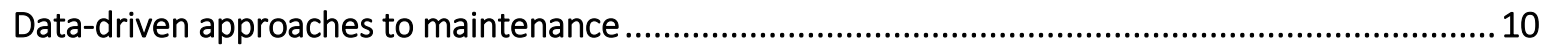

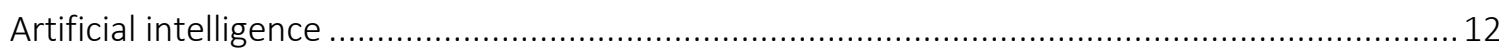

Applications of data-driven maintenance in transport sectors .................................................... 14

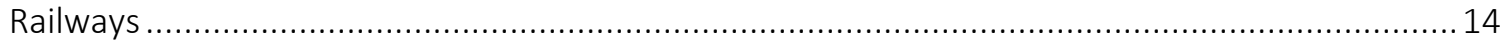

Roads .

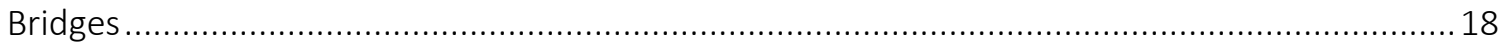

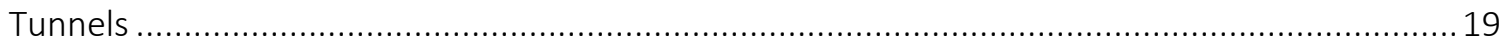

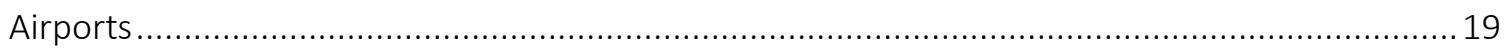

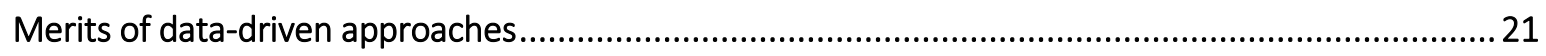

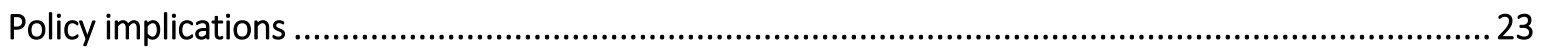

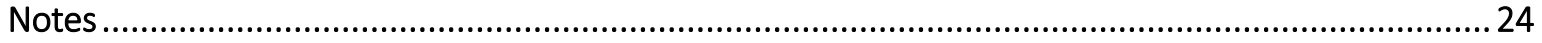

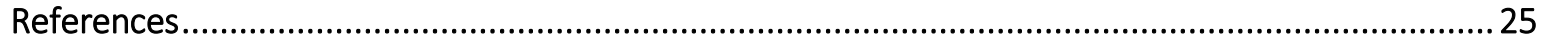

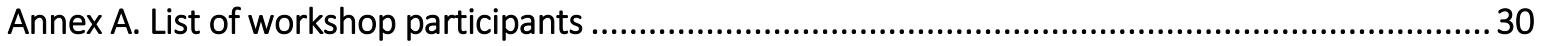




\section{Executive summary}

\section{What we did}

This report assesses the potential of data-driven approaches to improving transport infrastructure maintenance. It looks at trends in maintenance strategies, explores how the targeted use of data could make them more effective for different types of transport infrastructure, and looks into implications for policy. The report builds on discussions held during workshops with members of the International Transport Forum's Corporate Partnership Board.

\section{What we found}

Maintenance constitutes an inevitable, albeit often invisible, part of countries' transport policies. Increased demand for transport infrastructure accelerates infrastructure's ageing. The effects of climate change further aggravate this. Unsurprisingly, many governments look for transport infrastructure maintenance policies that provide better value for money than current practices offer.

Infrastructure maintenance strategies are gradually shifting towards data-driven approaches. They exploit the power of digital technologies, Big Data analytics and advanced forecasting methodologies. Data-driven approaches have gained momentum in transport infrastructure maintenance as a result of four simultaneous technological innovations.

First, the development of digital technologies has resulted in the digitalisation of society, industry and transport, which facilitates data sharing. Second, computing technologies have provided the necessary horsepower for running the digital infrastructure. Third, the Internet of Things and sensor technology have increased the potential for automating reporting from sensors that capture and measure new phenomena and provide data sets that flow through digital infrastructures. Fourth, artificial intelligence (AI) has helped to extract information from vast amounts of data, recognising patterns beyond the capacity of individual observation and exploiting digital infrastructure and computing power.

Policy makers are beginning to leverage these developments in various ways. Data-driven maintenance is becoming common in many parts of the transport industry.

Railroads collect massive amounts of inspection data from different sources using various methods, such as track inspection cars and drones that gather data to model track degradation. However, the rail sector faces numerous challenges for applying Big Data analysis: a lack of specific data analysis tools, high cost of involving stakeholders and heterogeneous data sources. Also, the algorithms currently used to predict the wear of rail infrastructure only work under lab conditions.

For road infrastructure, various automated inspection methods exist. These include vision-based methods, laser scanning, ground penetration radar and a combination of these. All are accurate and effective but usually costly. As a result, the coverage and collection frequency can prove insufficient for detecting 
changing road conditions. Several pilot studies have tried to use smartphones to collect data on the state of roads to reduce deployment costs for data-driven maintenance.

At airports, the demand for accurate real-time data has spawned systems that automatically acquire and process infrastructure data. Advanced technologies now register when deformities develop on runways. They accurately measure moisture levels, temperature, strain and other factors relevant to wear and degradation. Several airports have built, or plan to build, concrete pavements with embedded strain gauges and other sensors to monitor the stress in the material caused by aircraft.

Overall, data-driven approaches to infrastructure maintenance promise to enhance fact-based decision making and capabilities to predict the remaining useful life of assets. They can also improve cost efficiency and environmental sustainability. However, some new challenges need to be addressed, notably for the use of Al. Al predicts future behaviour based on historical data. Yet all predictions can prove incorrect where events do not follow past trends.

\section{What we recommend}

Scale up and speed up the deployment of data-driven approaches to transport infrastructure maintenance Transport infrastructure maintenance could benefit from a broader and accelerated roll-out of data-driven approaches. These could improve the quality of assets, enhance the life cycles and save costs - especially when the relevant technologies are well-known, such as sensor technologies. In some cases, more tests and pilot projects will be useful, notably where leveraging data technologies for more effective maintenance policies poses specific challenges, as is the case of artificial intelligence in the railway sector.

Update regulation and guidelines for transport infrastructure maintenance to facilitate the introduction of more data-driven approaches

Current regulations and guidelines apply to condition-based maintenance strategies. These may set requirements that are ill-adapted to data-driven approaches to maintenance and may hamper their rollout. Policy makers should ensure that the policies applied to data-driven approaches do not stifle their potential benefits.

\section{Ensure data-driven infrastructure maintenance approaches follow good practices in data governance}

The use of data in infrastructure maintenance must be in line with privacy protection laws and regulations. All data should be anonymised and encrypted. Location and trajectory data should be covered by the most robust protection methods, as they create the severest vulnerabilities for citizens. Tools to limit privacy risks include non-disclosure agreements between data users and providers, the involvement of trusted third parties to conduct the data collection and the development of "safe answers" approaches, in which only query results are exchanged instead of raw data. Governments could also broker data-sharing partnerships for the purpose of data-driven maintenance, for instance, between data providers and infrastructure managers. However, it may want to limit such partnerships to data of public interest and require purpose specificity and data minimisation. 


\section{The maintenance challenge}

Transport infrastructure, like all other types of infrastructure, tends to wear, tear, and deteriorate with age and use. As it is almost impossible to design a transport infrastructure system that is maintenancefree, maintenance constitutes an inevitable, but often invisible, part of countries' transport policies. Often, shortcomings in infrastructure design are compensated for with maintenance programmes (Kumar, 2009). Maintenance regimes are expected to ensure the performance and functionality for which the transport infrastructure assets were designed at the lowest possible costs. Performance can be defined in terms of quality, safety and environmental impacts.

Maintenance is defined as a combination of all technical, administrative and managerial actions during the life cycle of an item intended to maintain it in or restore it to a state in which it can perform the required function. Maintenance management relates to maintenance requirements, objectives, strategies and responsibilities, and implementation of them by such means as maintenance actions. These can include actions such as inspection, monitoring, repair and replacement.

The role of transport infrastructure maintenance has gained importance. Many infrastructures were conceptualised, designed and built without much reflection on maintenance requirements. Infrastructures are increasingly connected to each other, which means that failure in one infrastructure asset will affect the performance of the whole system. In addition, the demand for transport infrastructure has increased as more and more people use it. This accelerates the ageing of infrastructure and leads to the increased need for maintenance. However, strains on public budgets have often resulted in reductions in maintenance budgets. The situation is further aggravated by the effects of climate change bringing additional pressures on these infrastructures. Not surprisingly, many governments will be interested in transport infrastructure maintenance policies that can provide better value for money. This report analyses to what extent data-driven approaches could help to improve the effectiveness of maintenance policies in the transport sector.

Transport infrastructure managers broadly deploy two approaches to maintenance: corrective and preventive. Corrective maintenance consists of correcting infrastructure damages or failures ${ }^{1}$. Preventive maintenance aims to reduce the probability of infrastructure assets' failure and avoid deviations from agreed service levels. Corrective maintenance is also known as reactive maintenance, as it is undertaken after a defect or failure occurs. This strategy leads to high maintenance costs due to sudden failure and system recovery (Figueroa-García et al., 2015).

A preventive maintenance strategy involves the performance of maintenance activities before equipment fails. Preventive maintenance includes scheduled adjustments, major overhauls, replacements, renewals, and inspections. It can be carried out either during the system downtime or while the system is in operation. Its most significant advantage is that it can be planned in advance and performed when convenient (Budai-Balke, 2009). Preventive and conditional maintenance emerged because they could provide higher levels of safety and reduce maintenance in comparison with corrective maintenance (Fumeo et al., 2015). 
There are two forms of preventive maintenance:

- Predetermined maintenance: maintenance action is carried out according to a timeline established by a predetermined rule. The action is based either on time (e.g. once every six months) or on a measure of usage (e.g. the frequency of certain tonnages, loads, number of vehicles, etc.). The predetermined intervals are often established during the design and construction of infrastructure and frequently guided by national and international regulatory regimes.

- Condition-based maintenance: preventive maintenance that includes an assessment of the actual physical conditions. In condition-based maintenance, there is a measurable parameter that correlates with the degradation over time and the onset of failure. Changes in the measurable parameter are obtained from data collected using appropriate condition monitoring techniques. The two main techniques are direct and indirect measurement. Data-related technologies - such as sensor technologies - have been central to the increasing global use of condition-based maintenance policies for transport infrastructure.

Repeated analysis of the parameters of the infrastructure degradation (the condition) and relevant context information can help indicate the current physical health of assets (now-casting) and forecast the rate of degradation, the future state of the infrastructure and maintenance needs (predictive maintenance).

Organisations can also use maintenance policies as strategies to gain a competitive advantage in relation to the market, reduce downtime, and reduce overall operations costs. A maintenance strategy can help reduce costs of transport operations because maintenance represents a sizeable part of the costs of organisational assets. Such a strategy would need to reflect the balance desired between corrective and preventive maintenance. In addition, transport users want transport that generates the greatest satisfaction or the least external damage, for example, the safety of the system. In other words, users are willing to change their routes or pay more for an acceptable return. Thus, the cost involved in a maintenance operation goes well beyond the internal costs of an operation and may have a direct impact on the social welfare of the end consumer (De Souza and Filho, 2020).

Until the middle of the $20^{\text {th }}$ century, maintenance was simply viewed as an unavoidable cost to be incurred after the object was built and put into operation. There was a dramatic change after the Second World War. Reliability evolved as a new discipline and the theory of reliability dealt with various aspects such as the science of degradation of material and assets; the use of statistical methods to assess reliability and related maintenance needs and; mathematical models for predicting the rate of degradation of an asset and the importance of preventive maintenance. Investing in preventive maintenance lowers the cost of corrective maintenance but results in additional costs. Operational research techniques focussed on models to determine the optimal preventive maintenance to achieve a proper trade-off between corrective and preventive maintenance.

The next stage of evolution was the emergence of alternate approaches to the maintenance of objects in different industry sectors. Two that have been used extensively across the globe are reliability-centred maintenance (RCM), which had its origins in the airline industry, and total productive maintenance (TPM) which had its origins in manufacturing. Both have been adopted in modified forms by infrastructure managers of several organisations. Advances in technology, such as sensors, data collection, computers and communication, have resulted in the evolution of condition-based maintenance (CBM) and emaintenance (Karim, 2008; Karim et al., 2016; Ben-Daya, Kumar and Murthy, 2018).

Maintenance in the $21^{\text {st }}$ century has moved from the trial-and-error approach of the engineers of the early $20^{\text {th }}$ century to a multi-discipline subject founded on science, engineering and technology. Maintenance 
engineers and managers now need advanced techniques for failure and maintenance data analysis and building models for effective maintenance decision making. Maintenance strategies are gradually shifting towards data-driven approaches, exploiting the power of digital technologies, big data analytics and advanced forecasting methodologies. 


\section{Data-driven approaches to maintenance}

Data-driven approaches to transport infrastructure maintenance have gained momentum thanks to four simultaneous technological innovations. First, the development of digital technologies has resulted in the digitalisation of society, industry and transport, which facilitates data sharing. Second, computing technologies have provided society, industry and the transport industry with the necessary horsepower to run the digital infrastructure. Third, the Internet of Things (IOT) and sensor technology have increased the potential for the automation of reporting from sensors with the capability to sense and measure new phenomena. These are provided as data sets flowing through digital infrastructures. Finally, artificial intelligence (Al) has helped to extract information from vast amounts of data, recognising patterns beyond the capacity of individual observation, and exploiting digital infrastructure and computing power. Hence, the data-driven approach is understood here to consist of a complex, fact-based decision-making process using digital infrastructures, distributed computing, sensor data, and augmented analytics empowered by artificial intelligence.

Schematically, a data-driven approach to transport infrastructure maintenance consists of:

- information logistics: the availability and accessibility of data provided through an appropriate information logistics that represents the digital infrastructure.

- analytics: data must be processed, analysed and interpreted to make sense. The emerging digitalisation and artificial intelligence technologies are the main approaches to strengthening analytics. Analytics can be defined as a knowledge discovery platform through a set of algorithms, which are fed by data from the information logistic infrastructure.

- context-awareness: sensing the context in which a decision will be made, and adapting the analytics and information logistics to support the decision-making process. It represents a set of situations in which decisions will be made, i.e. the purpose of analytics.

In data science, these aspects are represented by a set of models such as information models, knowledge models, and context models, as depicted in Figure 1.

Figure 1. Main elements of data-driven approaches in transport maintenance

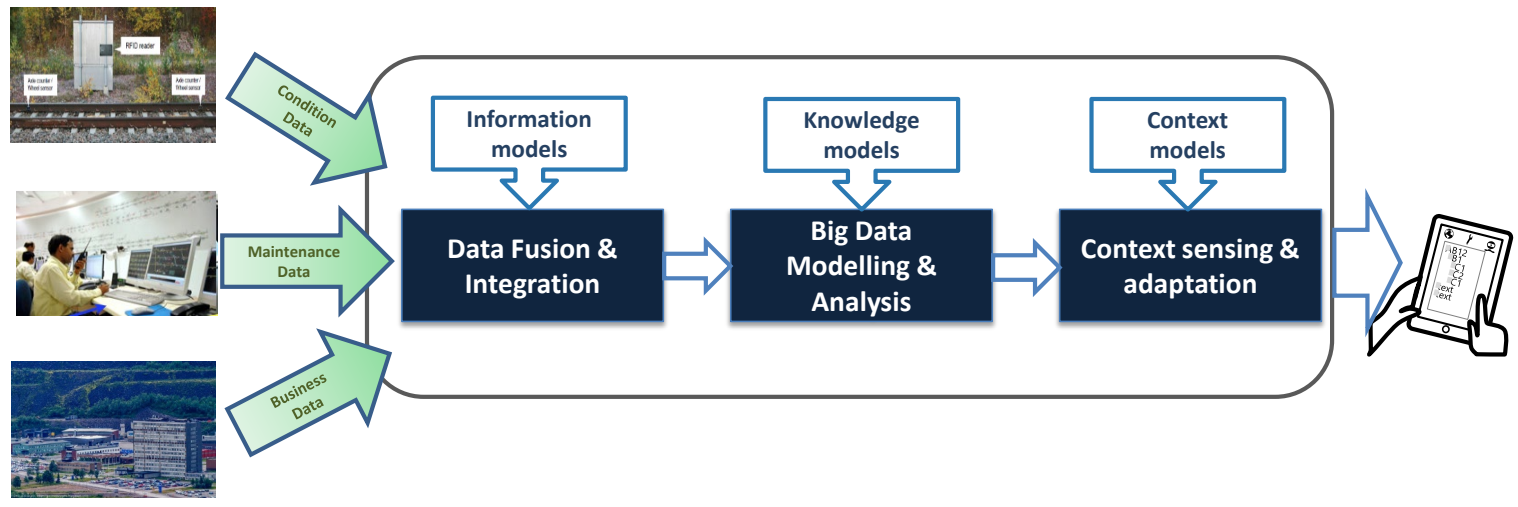

Source: Karim et al. (2016). 
Data can be structured or unstructured. Structured data have a well-defined format that requires closeended answers - a choice from a finite set of choices. In contrast, unstructured data are usually in the form of a text with no specified set of choices. For analysis, it is necessary to convert unstructured data, such as customer descriptions of problems, into structured data. This involves a natural language processing technique called named-entity extraction, also referred to as text tagging and annotation.

Data can generate information and knowledge that are needed to make proper maintenance management decisions. Maintenance data can be collected during maintenance actions and come from supplementary sources related to the asset, logistics, production and business (Table 1). Data can relate to quantitative indicators such as component failure times, component material property, load on the component, etc. Information is extracted from data through analysis to understand possible relationships, such as cause and effect, between pieces of data.

Table 1. Maintenance data for transport infrastructure

\begin{tabular}{|l|l|}
\hline Type of data & Examples \\
\hline Data collected during maintenance actions & $\begin{array}{l}\text { Data related to health of infrastructure: condition at inspection } \\
\text { Data related to maintenance actions: material, labour, costs, etc. }\end{array}$ \\
\hline Asset-related data & Detailed drawings, decomposition, failure and censored data, etc. \\
\hline Logistics-related data & Spare parts, repair-personnel and facilities, component suppliers, etc. \\
\hline Production-related data & Tonnage moved, output (in the case of production of processing plant) \\
\hline Business-related data & Service contracts, maintenance costs, etc. \\
\hline
\end{tabular}

Digitisation encompasses technologies that enable the process of transforming analogue data to digital data. Digitisation is necessary to achieve digitalisation, which can be defined as the provision of digital services that creates value to its user. Examples of digitisation technologies relevant to transport infrastructure are:

- stationary sensors and detectors: for measurement of wheel geometry, light beam, noise, loads, currents, etc.

- mobile sensors: for measurement of cracks, speed, noise, light beam, temperature, position, fluid, weather, navigation, etc.

Data from these sensors are necessary to enable a data-driven approach in the transport system. In addition, a data-driven approach also requires techniques and technologies for data integration, data filtering, data processing, and data visualisation. (Karim et al., 2016)

Digitalisation in any industry depends on the relationship between data, algorithms and models. Data can be seen as the fuel that is required to run an engine. The algorithm can be described as the engine that transforms one type of energy to another. The model is then the context in which the engine runs. The digitalisation of transport means that data points collected by a sensor, human or machine, are used to run algorithms that should contribute to fact-based decision making.

The dynamic and comprehensive information context related to the maintenance of complex technical systems with long life cycles emphasises the importance of appropriate information logistics (see Tsang, 2002; Blanchard, 2004; Muller et al., 2008). The main aim of information logistics is to provide just-in-time information to targeted users and optimisation of the information supply process, i.e. making the right 
information available at the right time and at the right point of location. Solutions for information logistics need to deal with:

- time management: "when to deliver"

- content management: "what to deliver"

- communication management: "how to deliver"

- context management: "where to deliver and why".

Frameworks, concepts, methodologies and platforms for the establishment of information logistics related to maintenance are often represented by the term e-Maintenance (Karim 2008).

\section{Artificial intelligence}

Artificial intelligence (AI) is an umbrella term for a set of technologies in which computer systems are programmed to model complex behaviour in challenging environments. Al is a major force driving innovation today, mimicking human intelligence in computer software. Intelligence can be described as the ability to learn from experiences, perceive abstract contexts, cognise, adapt to situations, and act (Karim et al., 2016). Hence, Al refers to a set of computer science techniques that allows computer software to learn, perceive, cognise and act.

One of the main approaches to Al is Deep Learning. This refers to interlinked nodes loosely modelled after the human brain that can be trained to recognise patterns quickly from data that would overwhelm the brain. It has been applied to tasks including detecting leukaemia earlier than human experts, driving cars, helping restaurants better predict their food demand, and optimising the logistics processes for global retail companies. (Modin and Andrén, 2021)

From an industrial point of view, Al technologies should be understood as methods and procedures that enable technical systems to perceive their environments through context and situation-awareness, process what they have monitored and modelled, solve certain problems, find novel solutions never found by humans, make decisions, and learn from experience to better manage the processes and tasks put under Al supervision.

Machine learning is one area of artificial intelligence used by industry. Machines need data to learn, either large quantities of data for one-time analytical purposes, or streams of data from which learning is continuously taking place. Based on data acquired either online or offline, machine learning can reduce complexity and detect events or patterns, make predictions, or enable actions to be taken without explicit programming in the form of the usual "if-then" routines or without classic automation and control engineering.

Al technologies are expected to increase the efficiency and effectiveness of industrial processes. The primary goals are to reduce costs, save time, improve quality and enhance the robustness of industrial processes. However, Al is not as well-used in industry as one might expect, given its potential. Integrating Al applications into corporate structures and along the entire value-added chain would entail enormous changes and high costs. At this point, Al applications tend to be found in the areas of robotics, knowledge management, quality control, and maintenance analytics shifting from traditional approaches to predictive ones. A good field for Al in maintenance in industrial environments is the analysis and interpretation of sensor data, distributed throughout equipment and facilities. IOT, i.e. distributed data suppliers and data users capable of communicating with each other, is the basis for this use of Al. IoT acquires the data after 
pre-processing, records the status of all different aspects of the machines, and performs actions in process workflows on the basis of its analysis. Its central purpose is to identify correlations that are not obvious to humans and enable predictive maintenance, for example, when complex interrelated mechanical setting parameters have to be adjusted in response to fluctuating conditions in the environment to avoid compromising the asset's health.

Artificial intelligence is also frequently used for data augmentation. This refers to techniques aimed at generating new synthetic data sets based on original data sets, e.g. by copying and slightly modifying or enriching the features in a data set. For example, a coloured photo can be augmented by generating a grey-scaled version of the same photo, and both the photos can then be fed to the Al-engine to increase its recognition capability. These techniques are commonly used in the learning phase of Al. 


\section{Applications of data-driven maintenance in transport sectors}

Data-driven approaches to maintenance are emerging in the transport industry. Digital technologies and artificial intelligence are used to increase the effectiveness of operations and maintenance. Such datadriven approaches can support diagnostics, prognostics and health management, perform condition monitoring and assessment, risk management, and asset management of infrastructure assets and systems. This section covers the data-driven maintenance approaches in different transport sectors.

\section{Railways}

Various technologies are used to monitor the condition of railway vehicles. These include acoustic bearing detectors, hot box detectors (HBD), temperature trending, hot and cold wheel detectors, track performance detectors, hunting detectors, wheel impact load detectors (WILD), cracked axle detectors, cracked wheel detectors and machine vision. In most cases, defective wheels generate high-impact load on the track, which is detected by WILD, as they weigh each wheel several times when the wheel passes a detector in a certain distance (Li et al., 2014). Strain-gauge-based technologies are used by WILD to measure the performance of a railcar in a dynamic mode by quantifying the force applied to the rail (Stratman et al., 2007). Once a train is detected, WILD generates different levels of data including train data, equipment data, track data and wheel data (Wang et al., 2018).

Conditions of railway track can degrade over time, either gradually or abruptly. This can occur due to cumulative tonnage, defective wheels, and the impulsive force on tracks. Defects can worsen if no recovery action is undertaken. They may finally result in complete rail breakage, which is a major cause of train derailment. Railway tracks have two different types of spot defects, namely, track structural defects and track geometry defects. Track structural defects occur when the structure and support system of the railway tracks fail. This could happen on the rail, ballast, ties system, sub-grade and drainage system. Track geometry defects arise due to irregularities in the various track geometry measurements such as profile, alignment and gauge (Zarembski, Einbinder and Attoh-Okine, 2016). The presence of structural defects such as cracks and track misalignment is a major threat to the safe operation of a railway system.

Railroads collect massive amounts of inspection data, including service failure data, signal data, ballast history, grinding history, remedial action history, traffic data, inspection data, as well as curve and grade data (Ghofrani, 2020; Ghofrani et al., 2018). These data are collected in different ways:

- Track inspection cars are used to detect the defects before they deteriorate. Two common types of monitoring cars are ordinary measurement cars, which measure the rail geometry and surface deterioration, and ultrasonic inspection (USI) cars, which measure rail breakage and internal cracks (Podofillini et al., 2006).

- Drones have also recently gained popularity for track inspections. Images are usually processed from the front camera of the drones (Pall et al., 2014). It is expected that fast image processing and analysis will be emerging in drone-based track inspection. 
- Track degradation models are used to better predict defects. They can be based either on the physical laws describing the behaviour of the asset known as mechanistic models or on datadriven models, which rely mainly on machine learning algorithms (Fumeo et al., 2015).

Preventive maintenance on tracks is expensive. Costs include inspection, different types of maintenance, track downtime, labour and material, among others. Preventive maintenance becomes worthwhile when the cost incurred by device failure is larger than that of preventive maintenance (Chen and Trivedi, 2005). Preventive maintenance is expensive when performed too early or too late.

Researchers have attempted to identify the most cost-effective maintenance policy. In an assessment of the track inspection and maintenance policy deployed for railroads in North America, Sharma et al. (2018) found that savings can be made by replacing repetitive minor maintenance actions with slightly more major maintenance actions. They termed this "optimal policy". The cost of major maintenance increases as the number of major maintenance actions increases. However, repeated minor maintenance on the same section of the track decreases, and their costs decrease in kind. The optimal policy is able to remove unnecessary minor maintenance.

\section{Box 1. Al Factory for Railways}

The Al Factory for Railways (AIF/R) aims to accelerate digitalisation in railways via a set of cloud/edgebased data services that provide capabilities such as acquisition, integration, transformation and the processing of railway-related data across endpoints.

AIF/R provides digital pipelines between data providers and data consumers. The platform enables the management and sharing of big data among many stakeholders with diversified requirements. AIF/R analyses characteristics of advanced analytic technologies such as Al, machine learning and deep learning. These capabilities are materialised in a set of interconnected and loosely coupled services that can be dynamically orchestrated to adapt to various contexts.

AIF/R's technology platform is a service-oriented, scalable environment that enables information logistics, including services data acquisition, data filtering, data quality, data transformation, cyber security, data processing, and visualisation. These services can be used to support such things as diagnostics, prognostics and health management, condition monitoring and assessment, risk management, asset management, etc. Furthermore, the platform will enhance the reliability, availability, and sustainability of the railway systems, including rolling stock and infrastructure, through the enablement of Industrial AI (IAI).

IAI is an applied research within Al that focuses on the deployment of Industrial Internet of Things, big data and context information in industrial contexts. IAI is explorative to bring insight and understanding of industrial phenomena, and it is also conclusive to generate problem-solving findings that are practically useful in various industrial contexts such as prescriptive analysis of asset health, diagnostics, and prognostics.

Source: LUT (2019).

There are various challenges for the application of big data analysis in the railway sector: for the moment, the sector lacks the specific data analysis tools it needs; it is costly to involve all the required stakeholders and; data sources are heterogeneous, ranging from the dynamic conditions of the vehicles, geographic information and weather characteristics to results from maintenance tasks. In addition, current algorithms 
to predict the wearing of rail infrastructure are limited to lab conditions but not applicable to real-life conditions (Thaduri et al., 2015).

Railways are complex technical systems. They have a large number of stakeholders and business models that include infrastructure owners, operators, maintenance service providers, consultants, etc. All stakeholders need to come to a common understanding of asset health management to implement a holistic system approach and strengthen the business competitiveness. The ongoing digitalisation and implementation of $\mathrm{Al}$ technologies in railway is highly dependent on the availability and accessibility of data for a geographically distributed system. An example of a platform for data sharing for the implementation of Al technologies in the railway sector is the Al Factory for Railways, developed by the Lulea Technical University (Box 1).

\section{Roads}

Road damage data are traditionally collected via road inspections. The current practice of road inspection relies heavily on a manual process. However, the frequency and coverage of such inspections are often limited due to budget constraints and workforce shortages. In addition, inspectors might suffer from potential evaluation bias and inconsistent evaluation criteria due to the subjective interpretation of standards (Ahn, Wang and Du, 2019).

Various automated road surface inspection methods have been proposed to overcome the limitations of manual inspection. Technological solutions that could be applied include vision-based methods, laser scanning, ground penetration radar, the natural lighting method and a combination of these (Ahn, Wang and Du, 2019; Yu et al. 2007).

The vision-based technologies aim to collect images of pavement or roads in real-time. Advances in highspeed camera technology and large-storage hardware have facilitated the collection of pavement images. As a result, academia and industry have paid more attention to automatic crack detection through pavement image processing, applying different processing methods. For example, they can identify the intensity of cracks and detect their edges. Machine-learning techniques have also been used in detecting pavement cracks. These methods are based on dividing a pavement image into a number of sub-images, each of which is represented by a vector of features extracted from the sub-image. These sub-images are then used for the training and classification for crack detection (Zou et al., 2012).

Laser scanning has been applied to deal with the limitations of vision-based technologies, namely their dependence on good lighting conditions, such as daytime and good weather. Image-based acquisition cannot robustly provide precise object geometry information under poor conditions. Recent advances in laser scanning technology have led to the integration of laser scanners on mobile mapping platforms. Mobile laser scanning can efficiently acquire very dense point clouds along road corridors. When integrated with a mobile mapping system, the data can be used to robustly capture the geometry of the road environment and for purposes of road surface inspection (Pu et al., 2012). Laurent et al. (2012) tested the use of car-mounted 3D laser scanners in automated road surface inspection.

The ground-penetrating radar (GPR) is a geophysical method that uses radar pulses to provide an image of the subsurface. It enables surveying the sub-surface to investigate underground utilities such as concrete and asphalt. GPR has proved its potential for road inspections, having several advantages, such as quasi-continuous measurements and the ability to map the sub-layers (Mahmoudzadeh et al., 2013). 
The dual-light inspection method, which uses multiple sources of light to retrieve images, enables engineers to retrieve depth information from images, see distance and inspect the distress of pavement automatically (Box 2). Su et al. (2012) describes the four steps of a dual-light inspection (DLI) method:

1. Two artificial lights capture two images by turning on alternative lights as a pair from an identical position and orientation.

2. The two images are combined to generate one subtracted image that presents the different pixels between the paired images.

3. An image-processing algorithm, such as one using edge-detecting and corner-detecting methods, enhances the distress features.

4. A classification algorithm categorises the images into groups with and without distress features.

Most of the technologies described above have their limitations. Despite their accuracy and effectiveness, they are usually costly. As such, the coverage and collection frequency can remain insufficient for detecting dynamically changing road conditions.

\section{Box 2. The "Road eye" system for monitoring road surfaces}

The grip of tires and the ease with which a vehicle navigates a road is greatly influenced by the road surface condition: if the road is dry or covered with water, ice, snow or slush. Certain weather conditions may create driving hazards and influence the maximum speed at which the vehicle can travel safely.

The "Road eye" system assesses the state of roads subjected to climate factors. It uses a vehicle equipped with an optical sensor to collect data. The sensor uses light sources of different wavelengths to illuminate the road surface and a detector to measure the reflected light from the road surface. The differences in absorption, scattering and polarisation help identify the state of the road: dry, wet, icy, snowy or slushy. The vehicle communicates the data and its position on the road in real-time to a special software. This data is used to divide the road into segments based on the state of the road. It is combined with Google Maps (using different colours for different conditions) and the information is available to the public.

The data is used by road maintenance departments to trigger various kinds of actions, such as changing the speed limits on different segments of roads and planning and initiating maintenance actions like snow ploughing or spreading sand on icy roads to improve driving conditions. The same technology can be used for data collection on dry roads to assess a road's degradation over time due to age and usage. This identifies the location and size of cracks and potholes, curb condition, etc.

Source: Casselgren, Rosendahl and Eliasson (2012).

To reduce deployment costs, various pilot studies have been developed to use regular smartphones to collect data on road conditions. Using regular phones makes data collection much easier than applying special equipment, but that ease comes at a cost: that of low-quality data. Many projects have focused on dealing with this challenge.

The demonstrated potential of the smartphone to monitor road surfaces can be used to develop a community sensor network by involving volunteers who can share information about road conditions while travelling (Alessandroni et al., 2014). In another project, smartphones were used for sensing the road surface condition from a moving vehicle via a smartphone application that collects acceleration data, 
processes the information, communicates it to a central server and visualises the road condition on Google maps (Kumar, Mukherjee and Singh, 2017). Smartphones can also be used to detect bumps and potholes by calculating the similarity of two signals based on template references (Singh et al., 2017). In another project, a smartphone sensor was used to detect braking events and bumps on the roads to characterise the type of road (Bhoraskar et al., 2012).

Another project adopts a machine learning approach to predict road conditions based on running vehicles' vibration data via sensors built into most smartphones. In addition, it analyses the data using deep learning technologies in order to weed out the noise contained in the data, such as the differences in vibrations related to different brands and conditions of vehicles, different weather conditions, different traffic conditions, and varying driving behaviours that can affect the quality and consistency of the collected data (Ahn, Wang and Du, 2019). Cabral et al. (2018) show that data collected via smartphones can also monitor damage on unpaved roads.

\section{Bridges}

Bridges are often classified as critical transport infrastructure. As such, it is essential they remain in good condition. Infrastructure managers often use condition monitoring tools and technology for planning maintenance actions and the life-cycle management of bridges. They also collect data from inspection and condition monitoring devices for managing maintenance and planning repair and replacement activities.

\section{Box 3. The Argo platform for infrastructure monitoring}

The Argo platform is a modular platform for infrastructure monitoring set up by three companies: Autostrade Tech, IBM and Fincantieri NexTech. Autostrade Tech is the system integrator and Centre of Excellence for Innovation of the Italian highway operator Autostrade per I'Italia (ASPI). IBM is a global information technology company. Fincantieri NexTech is part of the Fincantieri construction group that focuses particularly on shipbuilding. Fincantieri NexTech created the technological monitoring system of the new bridge in Genoa.

The Argo platform manages the data and processes related to the inspection and maintenance of Argo's infrastructure assets. Monitoring of the assets is based on distributed industrial loT technology. Drones inspect the infrastructure assets, photographing defects and creating a digital model (a "digital twin") of the asset. The digital twin is created through light detection and ranging technology. Together, these two technologies generate a highly precise "point cloud" (a set of data points in space). Artificial intelligence identifies and ranks anomalies in the assets, which are then communicated to the inspector. In this way, ASPI's infrastructure assets are digitalised and their inspection reports catalogued. Today, the platform supported by a mobile app - contains around 650000 elements of information, an average of 170 elements per asset.

Source: IBM (n.d.).

In most countries, the infrastructure manager follows national rules for bridge life-cycle management that invariably include service and maintenance, repair, and replacement planning for entire bridges or their components. As the operation and maintenance of bridges become more complex, infrastructure managers are adopting data-driven approaches to aid with decision making (Wu et al., 2020). An example 
of such an approach is the Argo platform, used by the Italian highway operator Autostrada per l'Italia (Box 3).

Maintenance data for bridges are qualitative or quantitative descriptions of a bridge, its components and the surrounding environment. Bridge profile data, traffic data and the surrounding environment, especially the transition zone connecting railway track or road infrastructure to the bridge, will influence the lifespan modelling of the bridges. Data describing the types of force the bridge endures and the bridge's corresponding structural response are critical for the lifespan model of bridge infrastructure and for maintenance planning (Wu et al., 2020).

Currently, most of the bridge maintenance data needs are defined by bridge inspection and maintenance manuals that usually require physical contact with the bridge structure. Bridge inspections often consist of visual observations, but these inspections are time-consuming and subjective. Developing inexpensive, easily deployable, non-contact sensing solutions suitable for field application could improve the inspection, monitoring and assessment of existing infrastructure. Developments in sensor technology, such as strain gauges, accelerometers, deflection gauges, etc., could boost the structural health monitoring (SHM) of bridges.

\section{Tunnels}

Tunnels are an important part of transport infrastructure. Their functionality at the design service level is critical for smoothly flowing traffic. Road or rail tunnel maintenance must be considered from the life cycle cost perspective. In underground rail systems, most of the operations depend on the serviceability of the tunnel networks. Tunnel networks of underground rail systems include the station structures, the traffic infrastructure, the ventilation networks, electrical wiring networks, etc. All these components must be in a functional state to achieve an acceptable service level of the tunnel. With the advent of new technologies, it is now possible to monitor and track the condition and functionality of these items. Longterm serviceability and behaviour can be evaluated by taking into consideration all tunnel features, such as geometry, geological and hydrogeological conditions, age, construction techniques, operation conditions and material quality.

\section{Airports}

Preventive maintenance is common practice in aviation. The industry has stringent requirements to repair or replace parts and systems before they fail. These requirements are based on engineering data but do not take into account the everyday operating conditions. Due to the variability of the actual experience, some good parts are replaced too soon, whereas others may fail before the prescribed replacement schedule. For this reason, airlines are increasingly turning towards predictive maintenance that takes into account the actual operating conditions of assets, which allows for maintenance planning before failure occurs. Many aircraft are equipped with sensors that generate information on vibrations and heat and fuel consumption that can be fed into analytics platforms and help identify patterns and trends that can direct maintenance strategies (Daily and Peterson, 2017). Airport infrastructure managers could leverage these data for analysis on the state of airport runways.

Efficient maintenance strategies at airports need a large amount of data about the state of airport facilities, the activities at the airport and its surroundings. The data must be accurate and readily available to the ground staff at any time. Although the ground staff can obtain data manually according to prescribed 
protocols, this activity is time-consuming and subject to human error. The data can be obtained and processed with automated procedures that are part of existing or developing geographic information systems. The demand for prompt, accurate data available in real-time has encouraged the development of systems that enable the automated acquisition and processing of data.

Traditionally, most airport authorities make maintenance decisions for airport pavements based on experience and appropriate established engineering practices. Since the mid-1980s, many airport agencies use the Airport Pavement Management System (APMS), a support system to develop cost-effective airport maintenance strategies. APMS follows a systematic procedure for determining needs and priorities, planning and scheduling maintenance, and required resource allocation. It delivers specific pavement network maintenance recommendations at an acceptable level of service after analysing the collected information and optimising the expenditures (Di Mascio and Moretti, 2019). APMS has significantly improved the pavement conditions in the United States (Moretti et al., 2017). The APMS also guides schedules for controls. In many US states, airport authorities should investigate an airport's functional conditions at 36-48 months and evaluate structural conditions through inspection of bearing capacity at a 60-month frequency.

Currently, a variety of indicators exist to measure the state of airport pavement, originally developed for measuring the performance of roads:

- The pavement condition index (PCI): Many aviation agencies apply this methodology, which was developed by the US Army Corps of Engineers. The PCI values are determined on the basis of visual inspection and identify the types of distress, the magnitude, and the quantities prevalent on the pavement surface. $\mathrm{PCl}$ indicates the rating of the pavement's condition. The scores range from 0 (failed) to 100 (excellent).

- Present serviceability index (PSI): This index was developed in the early 1960s and relates to the values of rutting, cracking, patching and pavement smoothness. Ratings are provided on a fivepoint distinct scale ( 0 for poor and 5 for excellent).

- International roughness index (IRI): The IRI is calculated from the road surface profile and computed using the surface elevation. The IRI has been applied broadly and adopted as a standard by the Federal Highway Performance Monitoring System.

While accurate measurements of the surface of the runway are very important, it is also necessary to find the cause of the emergence of deformities. Deformities occur on runways mostly due to the large forces at airplane landing, tectonic and meteorological changes, underground streams, or other causes. Two main types of deformations include surface deformations - such as cracks, humps and holes - and underground deformations, among which voids and underground cracks are the most frequent.

Advanced technologies now assess the emergence of deformities of runways and accurately measure moisture levels, temperature, strain and other factors relevant to wear and degradation. Chicago O'Hare Airport used dynamic strain gauges to examine the relative effectiveness of various isolation joint arrangements in the airport concrete pavements. Various airports - Shanghai, Hawaii, Newark - have built or plan to build concrete pavements with embedded strain gauges and other sensors in runway pavements or asphalt overlays to calculate the stresses induced by aircraft and supervise the propagation of horizontal shear deformation surface (Tofail et al., 2020). The use of 3D laser scanning with high resolution can help detect surface deformities on runways. Radar measurements can detect distortions of the surface, discovering the underground infrastructure, and finding cracks and voids and other anomalies in the lower structure of runways. This reduces the costs of restoration and runway maintenance. 


\section{Merits of data-driven approaches}

Data-driven approaches have evolved significantly over the last decades. With the re-emergence of Al technologies and digitalisation, the data-driven approach has become a tool for industry in general and the transport industry in particular. The data-driven approach promises to enhance fact-based decision making and capabilities to predict the remaining useful life of assets and improve cost efficiency and environmental sustainability.

Arguably, data-driven approaches increase objectivity, equity, and fairness. Artificial intelligence could positively influence the effectiveness of transport infrastructure maintenance. Machine learning can quickly compile historical data and create a risk map to assist with decisions. In addition, using a predictive model that has a learning component can account for variations in different subpopulations and potentially capture changes in risk over time. Data-driven approaches could result in the following advantages:

- Fact-based decision making: The increased computing capacity that enables the implementation of advanced $\mathrm{Al}$ algorithms empowers industry to process the ever-increasing data sets and to understand the correlations in the data. This, in turn, increases industry's insight to recognise and predict visible and hidden real-world phenomena. Embracing the data-driven approach could change the decision-making processes in the transport industry.

- Transparency via data-democratisation: A data-driven approach aides industries, like those in the transport sector, to share data and models. Increased availability and accessibility of data and models in a unified manner promotes transparency in decision making for organisations and individuals.

- Enhanced collaboration: A data-driven approach promotes a culture of communication and collaboration in industry through fact-based decision making in operation and maintenance. Enhanced collaboration increases the effectiveness and efficiency between organisations as well as that of their staff.

- Bias reduction: Intuition-based decision making in industry might lead to errors and disruptions in operation and maintenance. Data-driven approaches use a generic tool for analytics that reduces bias in decision making and inconsistency in the decisions made.

Despite the many advantages of data-driven approaches, they present new challenges that need to be addressed. When used inappropriately, artificial intelligence technology risks producing misleading results. As it uses past information to make predictions of future behaviour, artificial intelligence cannot account for unknown factors that could influence outcomes. As with all models, when future events do not follow historical trends, models can be rendered invalid. With the deployment of artificial intelligence this pitfall can become less obvious and needs explicit treatment.

Al algorithms are not generally biased, but the deterministic functionality of the Al model is subject to the tendencies of the data; therefore, the corresponding algorithm may unintentionally perpetuate biases if the data are biased. Biases in Al can surface in various ways. For example, the data may be insufficiently diverse, prompting the software to guess based on what it "knows." This suggests that the main objective 
of implementing a data-driven approach in transport should be to augment human intelligence. However, augmenting human intelligence is not just a matter of data provisioning, but this augmentation needs intelligence techniques - such as Deep Learning - to perceive and cognise data, and also to adapt to situations and act accordingly. Possible setbacks to data-driven approaches could be:

- Low-quality data: A data-driven approach consumes and analyses a massive amount of data that are collected from a number of data sources to bring insight to decision making. Poor data quality will lead to less accuracy and reliability.

- Blind trust: Data-driven approaches for analytics, as any approach, are built on assumptions, simplifications and descriptions of usage contexts. These assumptions and simplifications need to be measured, quantified and explained for decision makers. If decision makers do not fully understand the assumptions and the context, they may make poorly informed and inaccurate decisions.

- Knowledge transformation: Artificial intelligence is the means to transform know-how and experience into a set of algorithms. One of the main challenges for industry, then, when implementing data-driven approaches, is to maintain a high level of human knowledge resources as the organisation leans more and more on Al.

Data-driven approaches to transport maintenance are confronted with various challenges. One of those is data acquisition. In a data-driven approach, data is necessary to solve a problem. But how can one know which data sets can be used to describe a real-world phenomenon? How does one select the data that are significant for cognition?

Another challenge is related to the algorithms that process the data. Selecting the appropriate algorithm is a major optimisation challenge. Measuring the precision of the algorithm can be an indicator of its accuracy, but measuring model precision requires known knowledge for validation. So, what if the knowledge that describes a real-world phenomenon is not yet known? Can one enable explainability in algorithms to improve their trustworthiness?

Data-driven approaches are highly dependent on what is called domain knowledge. Domain knowledge refers to the understanding of particularities in an industrial sector, such as transport. Domain knowledge can be used, for instance, to describe the physics of failure, which is the understanding of the relationship between e.g. physical, thermal, chemical, electrical mechanisms over time within a given context. Understanding the physics of failure helps to select the relevant data sets and the most appropriate algorithms.

Furthermore, the strength of data-driven approaches is their ability to: transform high-dimensional, noisy data into lower-dimensional information for diagnostic or prognostic decisions; identify remaining useful life; and facilitate decision making in infrastructure maintenance (Dragomir et al., 2009). Data-driven techniques and machine learning have been increasingly applied in industry to estimate the remaining useful life of infrastructure and have shown improved performances over conventional approaches. In practice, however, it is not easy to apply data-driven approaches due to the lack of efficient procedures to obtain training data and specific domain knowledge. 


\section{Policy implications}

Governments are involved in transport infrastructure maintenance in various ways. Government agencies in many transport sectors act as infrastructure managers and are, as such, responsible for strategic maintenance of the infrastructure. They also provide maintenance budgets. In other transport sectors, governments have privatised infrastructure investment - and the connected decisions on maintenance and keep influence over maintenance strategies via concessions, licenses and contracts. At the same time, the government is also a regulator charged with regulating transport sectors and the way in which data can be shared. As such, governments try to guarantee safe, secure and effective transport and data governance systems. There can be trade-offs between the different roles - and interests - of governments. The role of policy makers is to find an appropriate balance in the context of these trade-offs.

Data-driven approaches to transport infrastructure maintenance have considerable potential advantages. They could provide more accurate insights into the actual state of the infrastructure asset than more traditional maintenance methods like regular physical inspections. The extent to which data-driven approaches are implemented and the timeline for each might differ according to the sector, place and specific context. For example, in the case of proven technology, policy makers might want to focus on the roll-out of good practices, whereas experimentation might be more suitable where it is unclear how new data technologies could be leveraged for more effective maintenance. Governments could also broker new data partnerships that could facilitate data-driven approaches. It may be wise to limit partnerships to data of public interest and to apply principles of purpose specificity (only providing data for a specific purpose) and data minimisation (limit the exchange to the minimal).

Policy makers should take into account good practices related to data governance when introducing initiatives for data-driven approaches. They should make sure that data-driven approaches comply with privacy protection regulations. This means that data should be anonymised and encrypted. Location and trajectory data are the most vulnerable, so they should be covered by the most robust protection methods. Policy makers should develop and endorse non-disclosure agreements, involve only trusted third parties and develop "safe answers" approaches, in which only query results are exchanged instead of raw data.

Data-driven approaches to transport infrastructure maintenance may necessitate more flexible regulations and guidelines. Current regulations and guidelines that apply to condition-based maintenance strategies may have requirements that are ill-adapted to the new approaches. Policy makers will need to ensure that the policies applied to data-driven approaches do not stifle their potential benefits. This implies updating transport infrastructure maintenance regulations and guidelines. 


\section{Notes}

1 Failure mechanisms can be grouped into overstress and wear-out mechanisms. In the case of overstress, an item fails only if the stress to which the item is subjected exceeds the strength of the item. If the stress is below the strength, the stress has no permanent effect on the item. In the case of wear-out, the stress causes damage that usually accumulates irreversibly. The accumulated damage does not disappear when the stress is removed, although sometimes annealing is possible. The cumulative damage does not cause any performance degradation as long as is it below the endurance limit. Once this limit is reached, the item fails. The effects of stresses are influenced by several factors -- geometry of the part, constitutive and damage properties of the materials, manufacturing and operational environment as discussed earlier. 


\section{References}

Ahn, C., C. Wang and J. Du (2019), Decision-Making Tool for Road Preventive Maintenance Using Vehicle Vibration Data, Data set, Project No. 18PLSU08, Texas A\&M University, https://digitalcommons.Isu.edu/ transet data/46.

Alessandroni, G. et al. (2014), "SmartRoadSense: Collaborative Road Surface Condition Monitoring," UBICOMM, Eighth International Conference on Mobile Ubiquitous Computing, System, Service and Technologies, DOI:10.13140/RG.2.1.3124.2726.

Aljumaili, M. (2016), Data Quality Assessment : Applied in Maintenance, PhD dissertation, Lulea University of Technology, http://ltu.diva-portal.org/smash/get/diva2:999247/FULLTEXT01.pdf.

Ben-Daya, M., U. Kumar and D. Prabhakar Murthy (2018), Introduction to Maintenance Engineering: Modelling, Optimization and Management, Wiley.

Bhoraskar, R., et al. (2012), "Wolverine: Traffic and road condition estimation using smartphone sensors", Conference paper presented at the fourth International Conference on Communication Systems and Networks, IEEE, New York, DOI: 10.1109/COMSNETS.2012.6151382.

Blanchard, B. (2004), Logistics Engineering and Management, Sixth edition, Prentice-Hall, Englewood Cliffs, New Jersey.

Budai-Balke, G. 2009, Operations Research Models for Scheduling Railway Infrastructure Maintenance, PhD Thesis, Erasmus University Rotterdam, hdl.handle.net/1765/16008

Cabral, F. et al. (2018), "An Automatic Survey System for Paved and Unpaved Road Classification and Road Anomaly Detection Using Smartphone Sensor", 2018 IEEE International Conference on Service Operations and Logistics, and Informatics, p. 65-70, doi: 10.1109/SOLI.2018.8476788.

Casselgren, J., S. Rosendahl and J. Eliasson (2012), "Road surface information system", Luleå University of Technology, Luleå, http://sirwec.org/wp-content/uploads/Papers/2012-Helsinki/66.pdf.

CEN (2017), "Maintenance: Maintenance terminology", EN 13306, European Committee for Standardization, Brussels.

Chen, D. and Trivedi, K., 2005, "Optimization for condition-based maintenance with semi-Markov decision process", Reliable Engineering \& Systems Safety, 25-29, https://doi.org/10.1016/i.ress.2004.11.001

CliMaint (2019), "Robust infrastructure - Adapting railway maintenance to climate change(CliMaint)", Sweden Project, Luleå University of Technology, https://www.Itu.se/research/subjects/Drift-ochunderhall/Forskningsprojekt/Pagaende-projekt/CliMaint?l=en.

Daily, J. and J. Peterson (2017), "Predictive Maintenance: How Big Data Analysis Can Improve Maintenance", in Richter, K. and J. Walther (eds.), Supply Chain Integration Challenges in Commercial Aerospace, Springer, https://doi.org/10.1007/978-3-319-46155-7 18. 
De Souza, N. and A. Filho (2020), "A systematic airport runway maintenance and inspection policy based on a delay time modeling approach", Automation in Construction, Vol. 110, https://doi.org/10.1016/j.autcon.2019.103039.

Di Mascio, P. and L. Moretti (2019), "Implementation of a pavement management system for maintenance and rehabilitation of airport surfaces", Case Studies Construction Materials, Vol. 11, https://doi.org/10.1016/j.cscm.2019.e00251.

Dragomir, O. et al. (2009). "Review of prognostic problem in condition-based maintenance", in 2009 European Control Conference (ECC), p. 1587-1592, doi: 10.23919/ECC.2009.7074633.

EEA (2020), "Towards a more sustainable transport system", website, European Environment Agency, https://www.eea.europa.eu/themes/transport (accessed 22 July 2021).

Figueroa-García, J. et al., 2015, "Multiple Experts Knowledge in Fuzzy Optimization of Logistic Networks", in: Kahraman, C., Onar, S. (eds.) "Intelligent Techniques in Engineering Management", Intelligent Systems Reference Library, vol.87, DOI: 10.1007/978-3-319-17906-3_24

Fumeo, E. et al., 2015, "Condition based maintenance in railway transportation systems based on big data streaming analysis", Procedia Computer Science, 53:1, 437-446, https://doi.org/10.1016/j.procs.2015.07.321

Ghofrani, F. (2020), "Data-Driven Railway Track Deterioration Modeling for Predictive Maintenance" Doctoral dissertation, State University of New York, Buffalo, https://www.proquest.com/openview/ $\underline{\text { dbb24444ecacfff50fffd39297c43df4/1?pq-origsite=gscholar \&cbl=18750\&diss=y. }}$.

Ghofrani, F. et al. (2018), "Recent applications of big data analytics in railway transportationsystems: A survey", Transportation Research Part C: EmergingTechnologies, Vol. 90, p. 226-246, https://doi.org/10.1016/j.trc.2018.03.010.

IBM (n.d.), "A singular focus on the road ahead: IoT and Al technologies transform roadway maintenance", webpage, IBM Corporation, https://www.ibm.com/case-studies/autostrade-italia/ (accessed 22 July 2021).

Karim, R. (2008), A Service-Oriented Approach to eMaintenance of Complex Technical Systems, Doctoral Thesis; Luleå University of Technology, Luleå, Sweden, http://ltu.diva-portal.org/smash/get/diva2: 990242/FULLTEXT01.pdf.

Karim, R. et al. (2016), "Maintenance Analytics: The New Know in Maintenance", IFAC-PapersOnLine, Vol. 49/28, p. 214-219, https://doi.org/10.1016/j.ifacol.2016.11.037.

Klimatanpassning (n.d.), "Myndigheternas regeringsuppdrag 2020" ("The authorities' government assignment 2020", website, https://www.klimatanpassning.se/vem-gor-vad/vad-gor-myndigheterna/ myndigheternas-regeringsuppdrag-2020-1.157874\#: :text=L\%C3\%A4nsstyrelserna\%20har\%20f\%C3\% B6r\%202020\%20inget\%20regeringsuppdrag\%20inom\%20klimatanpassning,uppdrag\%20framg\%C3\%A5r \%20av\%204\%20\%C2\%A7\%20och\%205\%20\%C2\%A7 (accessed 01 February 2021).

Koetse, M. and P. Rietveld (2009), "The impact of climate change and weather on transport: An overview of empirical findings", Transportation Research Part D: Transport and Environment, Vol. 14/3, p. 205-221, https://doi.org/10.1016/j.trd.2008.12.004.

Kour, R. (2020), Cybersecurity in Railway : A Framework for Improvement of Digital Asset Security, Doctoral thesis, Luleå University of Technology, http://urn.kb.se/resolve?urn=urn:nbn:se:Itu:diva-78488. 
Kumar, U. (2009), "System Maintenance: Trends in Management and Technology", in Handbook of Performability Engineering, Vol. 14/3, p. 205-221, https://link.springer.com/chapter/10.1007/978-184800-131-2 47.

Kumar, R., A. Mukherjee and V. P. Singh, (2017), "Community Sensor Network For Monitoring Road Roughness Using Smarphones," Journal of Computing in Civil Engineering, Vol. 31/3, https://ascelibrary.org/doi/10.1061/\%28ASCE\%29CP.1943-5487.0000624 (accessed 22 July 2021).

Laurent, J. et al. (2012), "Using 3D laser profiling sensors for the automated measurement of road surface conditions", in 7th RILEM International Conference on Cracking in Pavements, Scarpas, A. et al. (eds.), p. 157-167, https://link.springer.com/chapter/10.1007/978-94-007-4566-7 16 (accessed 22 July 2021).

LUT (2019), "LTU builds advanced Al factory for railway”, Luleå University of Technology, Luleå, https://www.Itu.se/centres/jvtc/Nyheter/Bygger-avancerad-Al-fabrik-for-jarnvag-1.194267?l=en (accessed 22 July 2021).

Mahmoudzadeh, M. et al. (2013), "Road inspection using full-wave inversion of far-field groundpenetrating radar data", in $7^{\text {th }}$ International Workshop on Advanced Ground Penetrating Radar, p. 1-6, doi: 10.1109/IWAGPR.2013.6601522.

Microsoft (n.d.), "Roadmap to Digital Infinity: How to Become an Itelligence Driven Organization", Microsoft, https://info.microsoft.com/rs/157-GQE-382/images/EN-CNTNT-eBook-SRGCM3914New.pdf (accessed on 22 July 2021).

Modin, A. and J. Andrén (eds.) (2021), The Essential Al Handbook For Leaders, Peltaroin AB, https://peltarion.com/peltarions-essential-ai-handbook-for-leaders.pdf.

Moretti, L. et al. (2017), "A runway veer-off risk assessment based on frequency model: Part I. probability analysis", in Dell'Acqua, G. and F. Wegman (eds.), Transport Infrastructure and Systems: Proceedings of the AllT International Congress on Transport Infrastructure and Systems (Rome, Italy, 10-12 April 2017), CRC Press, London.

Muller, A. et al., 2008, "On the concept of e-maintenance: review and current research", Reliability, Engineering and System Safety, 93:8, 1165-1187, https://doi.org/10.1016/j.ress.2007.08.006

Li, H. et al., 2014, "Improving rail network velocity; A machine learning approach to predictive maintenance", Transportation Research Part C: Emerging Technologies, 45:17-26,

https://doi.org/10.1016/i.trc.2014.04.013

Pall, E. et al., 2014, "Railway track following with the AR. Drone using vanishing point detection", Proceedings of 2014 IEEE International Conference on Automation, Quality and Testing, Robotics, DOI: $10.1109 / A Q T R .2014 .6857870$

Pintelon, L. and A. Paroi-Herz (2008), "Maintenance: An Evolutionary Perspective", in Complex System Maintenance Handbook, p. 21-48, Springer Series in Reliability Engineering, Springer, London, https://doi.org/10.1007/978-1-84800-011-7_2 .

Podofillini, L. et al., 2006, "Risk-informed optimization of railway tracks inspection and maintenance procedures", Reliable Engineering \& Systems Safety, 91:1, 20-35,

https://doi.org/10.1016/i.ress.2004.11.009 
Pu, S. et al. (2011), eRecognizing basic structures from mobile laser scanning data for road inventory studies", ISPRS Journal of Photogrammetry and Remote Sensing, Vol. 66/6, p. S28-S39, https://doi.org/10.1016/j.isprsjprs.2011.08.006.

Rail Baltica (2019), Study on Climate Change Impact Assessment for the Design, Construction, Maintenance and Operation of Rail Baltica Railway, Project no ${ }^{\circ} 18003094$, https://www.railbaltica.org/ wp-content/uploads/2019/09/CC final-report.pdf.

Schweikert, A. et al. (2014), "Climate Change and Infrastructure Impacts: Comparing the Impact on Roads in Ten Countries Through 2100", Procedia Engineering, Vol. 78, p. 306-316, https://doi.org/10.1016/ j.proeng.2014.07.072.

Sharma, S. et al. 2018, "Data-driven optimization of railway maintenance for track geometry", Transportation Research Part C, 90, 34-58, https://doi.org/10.1016/j.trc.2018.02.019

Singh, G. et al. (2017), "Smart patroling: An efficient road surface monitoring using smartphone sensors and crowdsourcing", Pervasice and Mobile Computing, Vol. 40, p. 71-88, https://doi.org/10.1016/j.pmcj. 2017.06.002.

Stratman, B. et al., 2007, "Structural health monitoring of railroad wheels using wheel impact load detectors", Journal of Failure Analysis and Prevention, 7:3, 218-225, https://link.springer.com/article/10.1007/s11668-007-9043-3

Su, Y.S. et al. (2012), "Dual-light Inspection Method for Automatic Pavement Surveys, Journal of Computing in Civil Engineering, Vol. 27/5, p. 534-543, DOI: 10.1061/(ASCE)CP.1943-5487.0000236.

Sun, Y. et al. (2019), "A Data-Driven Framework for Tunnel Infrastructure Maintenance", in International Conference on Applications and Techniques in Cyber Security and Intelligence, Abawajy J. et al. (eds), Vol. 842, Springer, https://doi.org/10.1007/978-3-319-98776-7 54.

Thaduri, A. et al., 2015, "Railway assets; A potential domain for big data analytics", Procedia Computer Science, Vol. 53: 457-467, https://doi.org/10.1016/j.procs.2015.07.323

Tofail, M. et al. (2020), "An overview of the airport pavement management systems (APMS)", International Journal of Pavement Research and Technology, Vol. 13, p. 581-590, https://doi.org/10.1007/s42947-020-6011-8.

Trafikverket (2020), "Digital vinterväglagsdata ger ökad säkerhet och framkomlighet" (Digital winter road team data provides increased safety and accessibility), press release, Trafikverket, www.trafikverket.se/ om-oss/pressrum/pressmeddelanden/Nationellt/2020/2020-10/digital-vintervaglagsdata-ger-okadsakerhet-och-framkomlighet/ (accessed 30 October 2020).

Tsang, A. (2002). "Strategic dimension of maintenance management", Journal of Quality in Maintenance Engineering, Vol. 8/1, p. 7-39, https://doi.org/10.1108/13552510210420577.

Wang, W. et al., 2018, "Joint Prediction of remaining useful life and failure type of train wheelsets: a multi-task learning approach", Journal of Transport Engineering, Part A: Systems, 144:6, https://ascelibrary.org/doi/abs/10.1061/JTEPBS.0000113

Wu, C. et al. (2020), "Critical review of data-driven decision-making in bridge operation and maintenance", Structure and Infrastructure Engineering, https://doi.org/10.1080/15732479.2020. 1833946.

Yu, S.J. et al. (2007), "3D reconstruction of road surfaces using an integrated multi-sensory approach", Optics and Lasers in Engineering, Vol. 45/7, p. 808-818, https://doi.org/10.1016/i.optlaseng.2006.12.007. 
Zarembski, A, Einbinder, D., and Attoh-Okine, N., 2016, "Using multiple adaptive regression to address the impact of track geometry on development of rail defects", Construction and Building Materials, 127, 546-555, https://doi.org/10.1016/i.conbuildmat.2016.10.012

Zou, Q. et al. (2012), "CrackTree: Automatic crack detection from pavement images, Pattern Recognition Letters, Vol. 33/3, p. 227-238, https://doi.org/10.1016/i.patrec.2011.11.004. 


\section{Annex A. List of workshop participants}

Carlos BERGERA, Head of External Relations Smart Mobility, Iberdrola

Phillippe CRIST, Advisor of Innovation and Foresight, International Transport Forum (ITF)

Faeze GHOFRANI, Assistant Teaching Professor of Rail Transportation Engineering, Penn State Altoona

Paulo HUMANES, Vice President Business Development and New Mobility, PTV Group

Christian IRMISCH, Business Development and Strategy, Siemens Mobility GmbH

Uday KUMAR, Professor and Head of the Division of Operation and Maintenance Engineering, Luleå University of Technology

Sharon MASTERSON, Manager, Corporate Partnership Board, ITF

Olaf MERK, Project Manager, ITF

Imogen PIERCE, Head of City Engagement and Integration, Arrival

Aquilino PONZIANI, Head of the International Department, Autostrade

Christophe POUTS, Portfolio Project Manager, ExxonMobil

Lorenzo ROSSI, CEO, Autostrade

María SANTOS ALFAGEME, Research Officer, Corporate Partnership Board, ITF

Jasja TIJINK, Senior Expert International, Kapsch TrafficCom AG

Philippe VENTEJOL, Independent Senior Consultant, RATP 


\section{EInternational Transport Forum}

\section{Data-driven Transport Infrastructure Maintenance}

This report examines the potential of data-driven approaches to improving transport infrastructure maintenance. It assesses trends in maintenance strategies, explores how the targeted use of data could make them more effective for different types of transport infrastructure, and looks into implications for policy. 